\title{
Understanding care of people with dementia in Spain: Cohabitation arrangements, rotation and rejection to long term care institution
}

\author{
Jesús Rivera $^{1 *}$, Felix Bermejo ${ }^{2}$, Manuel Franco $^{3}$, José Manuel Morales-González ${ }^{4}$ \\ and Julian Benito-León ${ }^{2}$ \\ ${ }^{1}$ Universidad de Salamanca, Departamento de Sociología y Comunicación, Facultad de Ciencias Sociales, Salamanca, \\ Spain \\ ${ }^{2} 12$ de Octubre Hospital, Neurology, Madrid, Spain \\ ${ }^{3}$ John Hopkins Bloomberg School of Public Health, Epidemiology, Baltimore, MD, USA \\ ${ }^{4}$ Ministry of Labor and Social Affairs, Director of Research Department, Madrid, Spain
}

\section{SUMMARY}

Background Most people with dementia in Spain live at home with their families. Current changes in the family structure are transforming the care of people with dementia through new cohabitation arrangenments and rotation practices.

Objective To describe the cohabitation arrangements of families of people with dementia in Spain and to understand the caregivers' characteristics related to rotation and the rejection of long term care institutions.

Methods A cross sectional study -NEDICES study- was conducted using both quantitative and qualitative methodologies.150 caregivers of people with dementia from two communities from Madrid, Spain, were surveyed using a questionnaire designed to describe cohabitation arrangements and care. Qualitative methods included: 13 caregivers participating in focus groups, and 3 caregivers in Semi Structured Interviews aimed to understand rotation practices and rejection to long term care institution.

Results Characteristics related with rotation were: sex of persons with dementia, widowhood, socio-economic status, caregiver relationship and burden of the caregiver. The qualitative study showed that the use of the rotation was related to normative behaviors and with obligation feelings, along with a change in the role of women in the current Spanish family. The use of long term care institutions was related to geographical distance of the family.

Conclusions The results of this study suggest that rotation has appeared in Spain as a new mechanism of care for people with dementia, and its related to the rejection of long term care institutions. Copyright (C) 2008 John Wiley \& Sons, Ltd.

KEY WORDS - dementia; long term care institutions; cohabitation arrangements; caregivers

\section{INTRODUCTION}

The care of people with dementia in Spain is mainly provided within the family. Nevertheless social changes in the last 30 years have altered the type of care and cohabition arrangement of elderly people in

\footnotetext{
*Correspondence to: J. Rivera, Universidad de Salamanca, Departamento de Sociología y Comunicación, Facultad de Ciencias Sociales, Avda. Francisco Tomás y Valiente s/n. Campus Unamuno, Salamanca, Spain, 37007. E-mail: jrivera@usal.es
}

general and particularly of people with dementia (Yanguas et al., 2000). Social changes such as larger numbers of elderly people living alone, changes in the women's role at home and new ways of understanding and putting up with family relations (Alberdi, 1999; Garrido, 2000; Pérez-Díaz et al., 2001; INE, 2004) have translated in unprecedented cohabitation arrangements and have led to different types of dementia care such as, for example, to live alternatively in several homes-'rotation' (Rivera, 2001; de la Cuesta, 2005; Losada et al., 2006). 
We combined qualitative and quantitative approaches to describe the cohabitation arrangements of people with dementia in Spain and to explain the causes of rejection of long term care institution of persons with dementia by caregivers and the rotation.

Very few studies have addressed how people with dementia live in Spain and, to our knowledge, no studies have explained the cohabitation arrangements according to latin and mediterranean countries, e.g. rotation (Marrugat, 2005), and the causes of rejection of the use of long term care institutions in Spain (Rivera et al., 1999; Bermejo, 2004).

\section{METHODS}

Quantitative data for these analyses were derived from the Neurological Disorders in Central Spain (NEDICES) cohort study, a longitudinal populationbased survey of the prevalence, incidence and determinants of older age-associated conditions of the elderly (Bermejo et al., 2001; Morales et al., 2004). Cross-sectional results from the NEDICES study have been already published elsewhere (BenitoLeón et al., 2004; De Toledo et al., 2004; Morales et al., 2004).

Qualitative data were based in a phenomelogical approach (Becker, 1998; Mckeown et al., 2004). The goal of phenomelogical research is to analyse how experience is built and communicated in the world of everydaylife (Holstein and Gubrium, 1998).

Focus groups (FG) were used in order to facilitate interactions between partiticipants about their experiences (Krueger and Casey, 2000). Using FG, the researchers are also allowed to consider issues and questions which they may not have previously considered (Madriz, 2000).

\section{Study design}

This study was conducted as a combination of quantitative and qualitative methodologies. The quantitative section is based on the study of caregivers proceeding from cohort study NEDICES. A sample of prevalent cases of dementia were selected and the caregivers of persons with dementia analyzed. The caregivers completed a questionnaire including the following variables: socio-demographics items, structured questions which analysed the care network, informal and formal care and standardized scalesZarit burden Scale (Zarit et al., 1980), Katz Index (Katz et al., 1963), Pearlin Scale (Pearlin et al., 1990).

The section of the study using qualitative methodology consisted in two FG and three consecutive interviews. FG were composed of caregivers of people
Table 1. Composition (and selection criteria) of FG

\begin{tabular}{ll}
\hline FG 1 Date: 02/06/2000 & FG 2 Date: 02/15/2000 \\
\hline $\begin{array}{l}\text { Medium-low social class } \\
\text { Females only }\end{array}$ & $\begin{array}{l}\text { Medium-high social class } \\
\text { Males and females } \\
\text { Daughters }\end{array}$ \\
$\begin{array}{l}\text { Daughters, husbands } \\
\text { and wives }\end{array}$ \\
Different kinds of & $\begin{array}{l}\text { Different kinds of living } \\
\text { cohabitation arrangement: }\end{array}$ \\
institution, family & family and living apart \\
or living apart from family & from family \\
Different kinds of dementia & Different kinds of \\
intensity & dementia intensity \\
Seven participants & Participants: three male \\
& and three female \\
\hline
\end{tabular}

with dementia. Caregivers discussed what they thought about the care provided to their relatives (difficulties and needs as caregivers, consequences of care in daily life and their opinion about the use of long term care institution). According to the results obtained from the FG, three semi-structured interviews (SSI) were designed, complementing the discourses showed in the FG. The composition of the FG and SSI, as well as selection criteria of the participants are shown in Table 1 and Table 2.

The following inclusion criteria for caregivers of people with dementia were applied: Age-participants aged 18 and older; Dementia severitycaregivers with relatives diagnosed with any kind of dementia according to DSM-III (mild, moderate and intense) (WHO, 1988); Time of care - caregivers must have provided care to a person who had been diagnosed with dementia for at least 1 year; and at least $1 \mathrm{~h}$ of daily assistance in the last year.

\section{Setting}

The quantitative part of this study took place in two communities from central Spain: (1) Las Margaritas, a

Table 2. Composition (and selection criteria) of SSI

\begin{tabular}{lll}
\hline SSI 1 & SSI 2 & SSI 3 \\
$\begin{array}{l}\text { Date:03/17/2000 } \\
\text { Proceeding from }\end{array}$ & Date:04/03/2000 & Date:04/25/2000 \\
informal contact & $\begin{array}{l}\text { Proceeding from } \\
\text { organizations }\end{array}$ & $\begin{array}{l}\text { Proceeding from } \\
\text { informal contact }\end{array}$ \\
& Male & Male \\
Male & Son-in-law & Son \\
Son & Medium-low & Medium-High \\
Medium-low & social class & social class \\
social class & Living in a & Living in several \\
Living in several & fingle family & families alternatively \\
families aternatively & sing & Moderate dementia \\
Intense dementia & Intense dementia & Moderaty \\
\hline
\end{tabular}


working-class neighborhood in Getafe (Greater Madrid); and (2) Lista, a professional-class neighborhood in Salamanca district (Central Madrid).

FG and SSI were set up in Madrid at the Spanish Association of Sociologists, because this place was considered a neutral space, necessary to conduct FG (Morgan, 1998). Each session was convened by an experienced FG moderator: first author in the FG and a research assistant, who collaborated in this survey, was present as a recorder.

\section{Participants and data collection}

The cases in the quantitative section of this study come from the NEDICES study (Morales et al., 2004), that was originaly designed with two phases. Phase 1 involved door-to door screening of eligible people. The screening included the use of standardized questionnaries administered by lay interviewers. Phase 2 involved a neurologist's examination of those individuals who screened positive in Phase 1. The stimated prevalence of dementia in the general study (Margaritas and Lista) were near 6\% (Benito-León et al., 2004; De Toledo et al., 2004). We used a sample of successive cases, once the previous diagnosis of dementia was confirmed by the study neurologist, the caregivers were interviewed. The first 150 caregivers of these persons diagnosed with dementia (belonging to the prevalent cases) that acepted the interview were included in the sample and were studied (43 cases were unreachable and could not be interviewed).

For the qualitative section of this study the members of the FG and SSI were selected from outpatient clinics, members of Alzheimer's family organizations and informal contacts. People who had previously answered the applied questionnare in the population study could not participate in FG or SSI, because their discourse would have been determined by the items from the quantitative questionnaire (Morgan, 1998). SSI were implemented only for male caregivers. Since men generally do not take on the role of caregiver, we did not consider it necessary to create a male caregivers FG; however, the individual trajectory of care in male caregivers was aim of interest and, therefore, was pertinent to perform SSI. The FG and interviews were performed in the winter and spring of 2000 and systematically recorded and analysed using the 'MAXqda' program. The quotation was literal, referring to the FG number and to the transcription page (e.g. 2FG, 5: 2; 2. p. 5); and in the case of interviews, the reference was also included in the transcription page (e.g. 3SI, 7; Semi-structured p. 3. 7).
The sample of caregivers from the qualitative section come from a different population than the ones in the quantitative section for two reasons: (a) persons who had answered questions in the quantitative section could not participate in FG and SSI because of the posibility of same source bias (Madriz, 2000); (b) demographic characteristics of caregivers in the qualitative section were very similar to those of the caregivers in the quantitative section; we considered that the discourse generated had been very similar if the caregivers proceeding from quantitative section would have participated in FG or SSI.

A list of themes for the FG were generated, which were regarding the main areas of concern for dementia sufferers caregivers, according to the scientific literature and previous research but without rejecting other domains not taken into account in these guidelines such as the perception of the family as caregiver of old people, strategies of care, and view of formal support (institutionalization of people with dementia). The SSI guideline was more strict than that of the FG, although the questions asked were similar.

\section{Data analysis}

In the quantitative study, statistical analyses were performed using SPSS software (version 11.0; SPSS, Inc.; Chicago, IL). All analysis were descriptive. Categorical variables were compared using chi-square tests.

In the qualitative study, an interpretative approach to analysis was adopted to understand the meaning of the caregivers' experiences.

\section{RESULTS}

\section{Quantitative study}

Main socio-demographics data (age, sex and marital status) from persons with dementia are presented in Table 3. In relation to the intensity of dementia (DSMIII-R) and etiology most of the cases presented severe dementia (60.6\%) and Alzheimer's disease as aetiology $(74 \%)$.

The main features related to cohabitation arrangements are shown in Table 4. We highlighted the percentage of elderly people who lived in long term care institution (20\%) and those who lived in several homes 'rotating' among several relatives (15.3\%); if we compare the studied populations, only the persons with dementia in Margaritas lived in several homes.

Features of primary caregivers are shown in Table 3. Women mainly assumed the role of primary care- 


\section{J. RIVERA $E T A L$.}

Table 3. Socio-demographics data of people with dementia and their caregivers

\begin{tabular}{|c|c|c|}
\hline & $\mathrm{N}$ & $\%$ \\
\hline \multicolumn{3}{|l|}{ Patient } \\
\hline Male & 39 & 26.0 \\
\hline Female & 111 & 74.0 \\
\hline \multicolumn{3}{|l|}{ Caregiver } \\
\hline Male & 33 & 22.0 \\
\hline Female & 117 & 78.0 \\
\hline \multicolumn{3}{|l|}{ Age } \\
\hline \multicolumn{3}{|c|}{ Patient $($ Media $=86 ; S D=6.5)$} \\
\hline $65-69$ & 1 & 0.7 \\
\hline $70-74$ & 8 & 5.3 \\
\hline $75-79$ & 14 & 9.3 \\
\hline $80-84$ & 31 & 20.7 \\
\hline $85-89$ & 47 & 31.3 \\
\hline More than 90 & 49 & 32.7 \\
\hline \multicolumn{3}{|c|}{ Caregiver $($ Media $=59.9 ; S D=13.6)$} \\
\hline $18-39$ & 6 & 4.0 \\
\hline $40-59$ & 88 & 58.7 \\
\hline $60-79$ & 37 & 24.6 \\
\hline More than 79 & 19 & 12.7 \\
\hline \multicolumn{3}{|l|}{ Marital status } \\
\hline \multicolumn{3}{|l|}{ Patient } \\
\hline Single & 14 & 9.3 \\
\hline Married & 41 & 27.3 \\
\hline Widower & 95 & 63.3 \\
\hline \multicolumn{3}{|l|}{ Caregiver } \\
\hline Single & 19 & 12.6 \\
\hline Married & 104 & 69.4 \\
\hline Separated/divorced & 5 & 3.4 \\
\hline Widower & 18 & 12.0 \\
\hline Not specified & 4 & 2.6 \\
\hline \multicolumn{3}{|c|}{ Relationship of caregiver with patient } \\
\hline Spouse & 31 & 20.7 \\
\hline Daughter & 70 & 46.7 \\
\hline Son & 15 & 10.0 \\
\hline Son and daughter-in-law & 12 & 7.9 \\
\hline Other & 22 & 14.7 \\
\hline
\end{tabular}

Table 4. Cohabitation arrangement of people with dementia according to neighbourhoods

\begin{tabular}{|c|c|c|c|c|c|c|}
\hline & \multicolumn{2}{|c|}{$\begin{array}{l}\text { Margari- } \\
\text { tas }\end{array}$} & \multicolumn{2}{|c|}{ Lista } & \multicolumn{2}{|c|}{ Total } \\
\hline & $\mathrm{N}$ & $\%$ & $\mathrm{~N}$ & $\%$ & $\mathrm{~N}$ & $\%$ \\
\hline \multicolumn{7}{|l|}{$\begin{array}{l}\text { Who did person with } \\
\text { dementia live with? }\end{array}$} \\
\hline Alone & 1 & 1.0 & 3 & 5.9 & 4 & 2.7 \\
\hline With steady family & 61 & 61.6 & 32 & 62.7 & 93 & 62.0 \\
\hline Several homes* & 23 & 23.2 & 0 & 0.0 & 23 & 15.3 \\
\hline In institution* & 14 & 14.1 & 16 & 31.4 & 30 & 20.0 \\
\hline \multicolumn{7}{|l|}{ Lived with steady family } \\
\hline Lived only with spouse & & & & & 35 & 37.6 \\
\hline Lived with sons & & & & & 58 & 62.4 \\
\hline
\end{tabular}

$* p<0.05$.
Table 5. Features of people with dementia and their caregivers according to living in one or several homes

\begin{tabular}{|c|c|c|c|c|}
\hline & \multicolumn{2}{|c|}{$\begin{array}{l}\text { Living in one } \\
\text { home }\end{array}$} & \multicolumn{2}{|c|}{$\begin{array}{l}\text { Living in } \\
\text { several homes } \\
\text { 'rotation' }\end{array}$} \\
\hline & $\mathrm{N}$ & $\%$ & $\mathrm{~N}$ & $\%$ \\
\hline \multicolumn{5}{|l|}{ Geder* } \\
\hline Male & 30 & 32.2 & 5 & 21.7 \\
\hline Female & 63 & 67.8 & 18 & 78.3 \\
\hline \multicolumn{5}{|l|}{ Persons with dementia's age } \\
\hline 65-79 years old & 20 & 21.5 & 0 & 0.0 \\
\hline More than 79 years old & 73 & 78.5 & 23 & 100.0 \\
\hline \multicolumn{5}{|l|}{ Marital status* } \\
\hline Single & 7 & 7.5 & 0 & 0.0 \\
\hline Widower & 40 & 43.0 & 23 & 100.0 \\
\hline Married & 46 & 49.5 & 0 & 0.0 \\
\hline \multicolumn{5}{|l|}{ Studied areas* } \\
\hline Margaritas & 61 & 65.5 & 23 & 100.0 \\
\hline Lista & 32 & 34.5 & 0 & 0.0 \\
\hline \multicolumn{5}{|l|}{ There are formal caregivers* } \\
\hline Yes & 24 & 25.8 & 1 & 4.3 \\
\hline No & 69 & 74.2 & 22 & 95.6 \\
\hline \multicolumn{5}{|l|}{ Caregiver relationship* } \\
\hline Spouse & 31 & 33.3 & 0 & 0.0 \\
\hline Son/daughter & 48 & 51.7 & 17 & 74.0 \\
\hline Son-in-law/daughter-in-law & 2 & 2.2 & 4 & 17.3 \\
\hline Grandson/granddaughter & 0 & 0.0 & 2 & 8.7 \\
\hline Others & 12 & 12.8 & 0 & 0.0 \\
\hline \multicolumn{5}{|l|}{$\begin{array}{l}\text { Zarit Scale** } \\
\text { (includes addition of all items) }\end{array}$} \\
\hline Never & 0 & 0.0 & 22 & 4.4 \\
\hline Almost never & 420 & 20.5 & 22 & 4.4 \\
\hline Sometimes & 133 & 6.5 & 22 & 4.4 \\
\hline Many times & 241 & 11.8 & 88 & 17.3 \\
\hline Almost always & 1252 & 61.2 & 352 & 69.5 \\
\hline
\end{tabular}

$* p>0.05 ; * * p=0.064$.

givers, with daughters of dementia patients being the caregiver in almost half of the cases.

Differential analyses between persons with dementia living alternatively in several homes and persons with dementia living in one home are shown in Table 5. Persons with dementia living in several homes were mainly women (almost 80\%). All persons with dementia living in several homes were widows living in the Margaritas neighbourhood.

\section{Qualitative study}

Care and motivation for primary caregivers: causes of cohabitation arrangements. Care justification was argued from two axes: obligation (norms) and mother love (feelings); on the one hand, obligation imposed by social rules and tradition and, on the other hand, love determined by a reciprocal feeling based on the belief that parents took care of their children or them. 
Sometimes even affective ties lead to gratification feelings in some caregivers.

'My mother has helped me a lot when I am at work and she has helped me to raise my son, then, if I can, I am going to take care of her'. (FG 1, 10).

When sons were the primary caregivers they seemed to have less anguish since they normally had more support than daughters within their homes and even shared such care proportionally with the wife (persons with dementia's daughter-in-law) and/or children (people with dementia's grandchildren):

'... there are people that due to their work or incompatibility of character between daughters and mothers or a father-in-law with his daughter-in-law and many times ... they think: I rather see her in a nursing home where she is taken care of, than having her here all day long fighting'. (FG 2, 35).

Married persons who took care of their spouses assumed this role. Although they did not need to argue about it, they thought it was an obligation (detached from marriage) and a love act coherent with ties made by a couple married for life.

During the last decades, social evolution has brought equality for women; nonetheless, most female caregivers wanted to go on taking care of their relatives, although with cooperation from the male part of the family in order that she can combine her role in public life with her role at home.

'... because if there is a strong family network then you say, with a little help that every one puts, wihtout involving too much, lightens a little, but on one person all the weight, it is very burdensome .... (FG2, 46).

'Rotation' and institutionalization: controversial cohabitation arrangement. 'Rotation' was used by caregivers participating in FG and SSI, and it was considered that the consequences for the persons with dementia could not be adequate, but it was the best option for caregivers before using a long term care institution. The use of the 'rotation' was related to normative behaviours and to obligation feelings, along with a change in 'role' of women in the Spanish family. Nevertheless the adoption of cohabitation developed into contradictions and guilty feelings, showing again the power of the tradition and social norms.

'... It seemed like those in the family who were opposed to send her to a nursing home loved her more than the others, and then we decided care her two months every one ...'. (SSE1, 2).

'.. no, I speak the truth, this situation of going from hand to hand and that nobody want to stay with her, as the song says, I do not agree, but I also understand, you begin to think, and it is not logical, that is years and years taking care of her mother .... (2FG, 25-26).

Nursing homes for relatives were strongly rejected in the discourses or considered the last resource. The wrong image of long term care institution was related to family failure, and the long term care institution was identified with abandonment. There were two confronted mentalities, one traditional which identified long term care institutions with asylums where people lived with nothing or no one, and a modern one which perceived long care term institutions as a resource without negative connotations. Women felt guiltier than men when they talked about the possibility of their relatives living in a long term care institution. Caregivers, detractors of entrance in long term care institutions, connected the institutionalization with family distance and with no love feelings of relatives towards persons with dementia. These rejections were exclusively towards long term care institution, not towards day centres or to institutional respite care.

'... Every elderly who has some relatives is being supported but if they have none, they must go to public long term care institutions, where nobody goes to visit them ... the situation is really sad ... (1FG, 7).

\section{DISCUSSION}

The aim of this study was to analyse cohabitation arrangements such as rotation and to study the causes that explain the rejection of institutionalization and rotation in Spain. Two different methodologies were used in this study.

Data about cohabitation arrangements showed, in general, percentages similar to data shown by other surveys (Fischer and Lieberman, 1999; Canadian Study of Health and Aging Working Group, 2002), except from the issues of 'rotation' and institutionalization:

'Rotation' or cohabitation arrangement of dementia patients in several homes is a care strategy that has only been mentioned and analysed in surveys that studied elderly people in general or disabled elderly (not exclusively dementia) (Rodríguez, 1994; Colectivo IOE/INSERSO/CIS/Instituto de la mujer, 1995; Rivera, 2001; de la Cuesta, 2006). In this survey, 
'rotation' was used only in a medium-low socioeconomic level urban area (Margaritas), and its main aim was to share the burden of care between family members. Three features of rotation stand out: (1) rotation took place in low socio-economic level places-Margaritas neighbourhood; (2) all caregivers belonged to second and third generation; (3) caregivers had a higher score in the Zarit scale.

Institutionalization of persons with dementia in our study sample was low if we compare these data to other studies outside of Spain (Grafstrom et al., 1992; Fisher and Lieberman, 1999; Canadian Study of Health and Aging Working Group, 2002). A possible explanation for this difference is that institutionalization of elderly people in Spain is very low (Fundación Encuentro, 2001). Nevertheless, in the higher income neighborhood of Lista, the elderly lived in nursing homes, indicating that, in Spain, more people with dementia from high socio-economic levels live in nursing homes than those from low socio-economic levels (García Navarro, 2000).

The data from caregivers who participated in the FG and SSI-, who rejected the idea of their relatives living in long term care institutions, had a profound sense of family participation (which included encouraging the patients to participate in self-care and occupational activities) (Vallone et al., 2002; Ho et al., 2003).

The use of nursing homes for people of medium class in Spain remains uncommon because of its high cost or because of being reserved for persons of extremely low resources, nevertheless we consider that the rejection of long care institutions is rooted primarily in cultural factors rather than economic factors as participants in the FG did not argue economic factors for not placing family members suffering from dementia in long term care institutions.

We need to acknowledge the main limitation in our study. It would have been desirable to have included two FGs: one composed of only women of mediumhigh social class and another one composed of women of medium-low class. This addition would have strenghthed our results.

On the basis of our results we recommend two specific policies: diversification of aids to the families and people with dementia, and direct colaboration of voluntary organizations with the National Health System and the Ministry of Social Affairs.

In conclusion, the results of this study suggest that societal changes in Spain have translated into new strategies to cope with the care of people with dementia; we specifically describe 'rotation', as a new mechanism of care, which is directly related to the rejection of long term care institutions.

\section{CONFLICT OF INTEREST}

None known.

\section{REFERENCES}

Alberdi IA. 1999. La nueva familia española. Editorial Taurus: Madrid.

Becker CS. 1998. Living and Relating: An Introduction to Phenomenology. Sage Publications: London.

Benito-León J, Bermejo-Pareja F, Morales-Gonzalez JM, et al. 2004. Incidence of Parkinson disease and parkinsonism in three elderly populations of central Spain. Neurology 62: 734741.

Bermejo FP (ed.). 2004. Aspectos familiares y sociales del paciente con demencia. Días de Santos SA: Madrid.

Bermejo F, Gabriel R, Vega S, et al. and the Neurological Disorders in Central Spain (NEDICES) Study Group. 2001. Problems and issues with door-to-door, two-phase surveys: an illustration from central Spain. Neuroepidemiology 20: 225-231.

Canadian Study of Health and Aging Working Group. 2002. Patterns and health effects of caring for people with dementia: the impact of changing cognitive and residential status. Gerontologist 42 : 643-652.

COLECTIVO IOE/INSERSO/CIS/INSTITUTO DE LA MUJER. 1995. Cuidados en la vejez. El apoyo informal. Ministerio de Asuntos Sociales: Madrid.

De la Cuesta C, Sandelowski M. 2005. Tenerlos en casa: the material world and craft of family caregiving for relatives with dementia. J. Transcult Nurs 16: 218-225.

De Toledo M, Bermejo-Pareja F, Vega-Quiroga S, Munoz-Garcia D. 2004. Behavioural disorders in Alzheimer's disease. Data from a populational study. Rev Neurol 38: 901-905.

Fisher L, Lieberman MA. 1999. A longitudinal study of predictors of nursing home placement for patients with dementia: the contribution of family characteristics. Gerontologist 39: 677686.

Fundación Encuentro. 2001. Informe España 2001. Fundación Encuentro: Madrid.

García Navarro JA. 2000. Psicopatología del anciano. Datos epidemiológicos. Revista Mult Gerontol 10: 82-88.

Garrido MIG. 2000. La política social de la familia en la Unión Europea. Ed. Dykinson: Madrid.

Grafstrom M, Fratiglione L, Sadman PO, Winblad D. 1992. Health and social consequences for relatives of demented and nondemented elderly. A. population-based study. J. Clin Epidemiol 45: 861-870.

Ho B, Friedland J, Rappolt S, Noh S. 2003. Caregiving for relatives with Alzheimeŕs disease: feelings of Chinese-Canadian women. J. Aging Stud 17: 301-321.

Holstein JA, Gubrium JF. 1998. Phenomelogy, ehnomethodology, and interpretive practice, In Strategies of Qualitative Inquiry, Denzin NK, Lincoln YB (eds). Sage Publications: London.

INE. 2004. Tendencias demográficas durante el siglo XX en España. Instituto Nacional de Estadística: Madrid.

Katz S, Ford AB, Moskowitz RW, et al. 1963. Studies of illness in the aged. The index of ADL: a standardized measure of biologidcal and psychosocial function. JAMA 94: 914-919.

Krueger RA, Casey MA. 2000. A Practical Guide for Applied Research, 3rd edn. Sage Publications: London.

Losada AB, Robinson Shurgot G, Knight BG, et al. 2006. Crosscultural study comparing the association of familism with burden 


\section{CARE OF PEOPLE WITH DEMENTIA IN SPAIN}

and depressive symptoms in two samples of Hispanic dementia caregivers. Aging Ment Health 10: 69-76.

Madriz E. 2000. Focus Groups in feminist research. In Handbook of Qualitative Research, Denzin NK, Lincoln YS (eds). Sage Publications: London; 835-850.

Marrugat ML. 2005. La familia cuidadora y su incidencia en la calidad de vida de las personas dependientes. Rev Mult Gerontol 15: $171-177$.

Mckeown LP, Porter-Armstrong AP, Baxter GD. 2004. Caregivers of people with multiple sclerosis: experiences of support. Mult Scler 10: $219-230$.

Morales JM, Bermejo F, Benito-León J, et al. 2004. Methods and demographic findings of the baseline survey of the NEDICES cohort. A. door-to-door survey of neurological disorders in three communities from Central Spain. Public Health 118: 426433.

Morgan DL. 1998. Planning Focus Groups. Sage Publications: London.

Pearlin LI, Mullan JT, Semple SJ, Skaff M. 1990. Caregiving and the stress process: an overview of concepts and their measures. Gerontologist 30: 585-594.
Pérez-Díaz V, Rodríguez C, Sánchez-Ferrer L. 2001. La familia española ante la educación de sus hijos, Fundación La Caixa. Colección de Estudios Sociales, número 5: Barcelona.

Rivera J. 2001. Redes familiares en el cuidado del anciano con demencia. Análisis de un estudio poblacional. Consejo Económico y social. Comunidad de Madrid: Madrid.

Rivera JN, Rivera SN, Zurdo AA. 1999. Revista Multidisciplinar de Gerontología. 9: 225-232.

Rodríguez JA. 1994. Envejecimiento y familia. Centro de Investigaciones Sociológicas: Madrid.

Vallone E, Sansoni J, Cohen MZ. 2002. The experience of Italians caring for family members with Alzheimer's disease. J. Nurs Scholarsh 34: 323-329.

WHO: ICD-10. Chapter V. 1988. Mental, behavioral and developmental disorders. WHO: Geneva.

Yanguas JJL, Leturia FJA, Leturia MA. 2000. Apoyo informal y cuidado de las personas mayores dependientes. Papeles del psicólogo 76: 112-120.

Zarit SH, Reever KE, Bach-Peterson J. 1980. Relatives of the impaired elderly: correlates of feeling of burden. Gerontologist 20: 649-655. 